\title{
Adduct of the blistering warfare agent sesquimustard with human serum albumin and its mass spectrometric identification for biomedical verification of exposure
}

\author{
Marc-Michael Blum ${ }^{1} \cdot$ Annika Richter ${ }^{2} \cdot$ Markus Siegert $^{2,3} \cdot$ Horst Thiermann $^{3} \cdot$ Harald John $^{3}$ \\ Received: 10 July 2020 / Revised: 7 August 2020 / Accepted: 25 August 2020 / Published online: 9 September 2020 \\ (C) The Author(s) 2020
}

\begin{abstract}
Apart from the well-known sulfur mustard (SM), additional sulfur-containing blistering chemical warfare agents exist. Sesquimustard (Q) is one of them and five times more blistering than SM. It is a common impurity in mustard mixtures and regularly found in old munitions but can also be used in pure form. Compared to the extensive literature on SM, very little experimental data is available on $\mathrm{Q}$ and no protein biomarkers of exposure have been reported. We herein report for the first time the adduct of $\mathrm{Q}$ with the nucleophilic $\mathrm{Cys}^{34}$ residue of human serum albumin (HSA) formed in vitro and introduce two novel bioanalytical procedures for detection. After proteolysis of this HSA adduct catalyzed either by pronase or by proteinase K, two biomarkers were identified by high-resolution tandem mass spectrometry (MS/HR MS), namely a dipeptide and a tripeptide, both alkylated at their Cys residue, which we refer to as HETETE-CP and HETETE-CPF. HETETE represents the Q-derived thioalkyl moiety bearing a terminal hydroxyl group: "hydroxyethylthioethylthioethyl." Targeting both peptide markers from plasma, a micro liquid chromatography-electrospray ionization tandem mass spectrometry method working in the selected reaction monitoring mode ( $\mu$ LC-ESI MS/MS SRM) was developed and validated as well suited for the verification of exposure to $Q$. Fulfilling the quality criteria defined by the Organisation for the Prohibition of Chemical Weapons, the novel methods enable the detection of exposure to $\mathrm{Q}$ alone or in mixtures with SM. We further report on the relative reactivity of Q compared to SM. Based on experiments making use of partially deuterated $\mathrm{Q}$ as the alkylating agent, we rule out a major role for six-membered ring sulfonium ions as relevant reactive species in the alkylation of $\mathrm{Cys}^{34}$. Furthermore, the results of molecular dynamics simulations are indicative that the protein environment around $\mathrm{Cys}^{34}$ allows adduct formation with elongated but not bulky molecules such as Q, and identify important hydrogen bonding interactions and hydrophobic contacts.
\end{abstract}

Keywords Hydroxyethylthioethyl $\cdot$ Protein adduct $\cdot$ Sulfur mustard $\cdot$ Verification $\cdot$ Vesicant

\section{Abbreviations}

Atr- $d_{3}$

BioPT

Atropine, triple deuterated

OPCW biomedical proficiency test

Electronic supplementary material The online version of this article (https://doi.org/10.1007/s00216-020-02917-w ) contains supplementary material, which is available to authorized users.

Harald John

haraldjohn@bundeswehr.org

1 Blum - Scientific Services, Björnsonweg 70d, 22587 Hamburg, Germany

2 Department of Chemistry, Humboldt-Universität zu Berlin, Brook-Taylor-Straße 2, 12489 Berlin, Germany

3 Bundeswehr Institute of Pharmacology and Toxicology, Neuherbergstraße 11, 80937 Munich, Germany

$\begin{array}{ll}\text { CE } & \text { Collision energy } \\ \text { CID } & \text { Collision-induced dissociation } \\ \text { CWC } & \text { Chemical Weapons Convention } \\ \text { ESI } & \text { Electrospray ionization } \\ \text { HETE } & \text { Hydroxyethylthioethyl moiety } \\ \text { HETETE } & \text { Hydroxyethylthioethylthioethyl moiety } \\ \text { HR MS } & \text { High-resolution mass spectrometry } \\ \text { HSA } & \text { Human serum albumin } \\ \text { LC } & \text { Liquid chromatography } \\ \text { LCt } & \text { Median lethal concentration after inhalation } \\ \text { logP } & \text { Partition coefficient in octanol/water } \\ \text { LOI } & \text { Limit of identification } \\ \text { MD } & \text { Molecular dynamics } \\ \text { MS } & \text { Mass spectrometry } \\ \text { MS/MS } & \text { Tandem mass spectrometry } \\ \text { NMR } & \text { Nuclear magnetic resonance }\end{array}$




\begin{tabular}{|c|c|}
\hline OPCW & $\begin{array}{l}\text { Organisation for the Prohibition } \\
\text { of Chemical Weapons }\end{array}$ \\
\hline Q & Sesquimustard \\
\hline RMSD & Root mean square deviation \\
\hline RMSF & Root mean square fluctuation \\
\hline RT & Room temperature \\
\hline SM & Sulfur mustard \\
\hline SRM & Selected reaction monitoring \\
\hline $\mathrm{S}_{\gamma}$ & Sulfur atom of cysteine residue side chain \\
\hline$t_{\mathrm{R}}$ & Retention time \\
\hline $\mathrm{XIC}$ & Extracted ion chromatogram \\
\hline$\mu \mathrm{LC}$ & Micro liquid chromatography \\
\hline
\end{tabular}

\section{Introduction}

Vesicants, chemicals that cause blistering of the skin, have been used as warfare agents for more than 100 years. The most prominent member of this group is sulfur mustard (SM, bis(2chloroethyl) sulfide, CAS 505-60-2, Fig. 1a) [1, 2]. It has been employed as recently as 2015 and 2016 by the terrorist group "Islamic State" in the Syrian Arab Republic and northern Iraq [3]. SM causes painful blisters and erythema on exposed skin areas characterized by delayed and complicated wound healing and shows a complex toxicokinetic behavior $[1,4]$.

a<smiles>ClCCSCCCl</smiles><smiles>ClCCSCCSCCCl</smiles><smiles>[2H]C([2H])(SCCCl)C([2H])([2H])SCCCl</smiles>

d<smiles>ClCC[S+]1CC1</smiles>

e<smiles>ClCCSCC[S+]1CC1</smiles>

$\mathbf{f}$

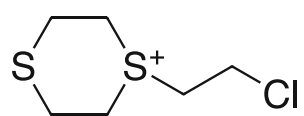

Fig. 1 Chemical structures of blister agents and their reactive intermediates: a sulfur mustard (SM), b sesquimustard (Q), c sesquimustard- $d_{4}$, d reactive episulfonium ions of $\mathrm{SM}$, e reactive episulfonium ions of $\mathbf{Q}$, and $\mathbf{f}$ the six-membered ring sulfonium ion of $\mathrm{Q}$
Verification of exposure is an important capability in order to guide medical therapy of casualties but also for generating evidence that a violation of the international norm on the nonuse of chemical weapons has occurred [5]. This norm is laid down in the Chemical Weapons Convention (CWC), which entered into force in 1997, and is implemented by the Organisation for the Prohibition of Chemical Weapons (OPCW) [6]. The OPCW designates laboratories for the analysis of authentic biomedical samples through successful participation in biomedical proficiency tests (BioPTs). In these BioPTs, samples of biological fluids spiked with SM represent a regular analytical challenge. The most long-lasting in vivo biomarkers of exposure are protein-adducts such as those formed with human serum albumin (HSA). HSA-adducts result from covalent linkage of SM to, e.g., the $\mathrm{Cys}^{34}$ residue, and have emerged as the most prominent biomarkers [7-10]. They have been used on several occasions for the analysis of samples from OPCW interlaboratory exercises but also from exposed victims [11-14].

However, SM is not the only blistering agent causing a serious threat for military personnel as well as for civilians. Among the chemicals listed in the Annex on Chemicals of the CWC are a number of higher sulfur mustards, including sesquimustard (Q, Fig. 1b).

Q (1,2-bis(2-chloroethylthio) ethane, CAS 3563-36-8, Fig. 1b), a white solid (melting point $56.6^{\circ} \mathrm{C}$ ), is about five times more blistering than SM [15]. As a solid, it represents a very persistent contact hazard but has so far not been used in its pure form. It was produced as a component in the British HQ process during World War II resulting in a 70:30 w/w mixture of SM:Q [16]. It is also regularly found in old distilled (HD) and Levinstein $(\mathrm{H})$ mustard. For example, a ton container of Levinstein mustard sampled in the USA after 60 years of storage before destruction contained about $10 \% \mathrm{w} / \mathrm{w}$ of Q [17].

Despite its relevance, the number of scientific publications on Q is small, especially when compared with the extensive literature on SM. Q was first reported by Bennett and Whincop in 1921 [18]. Its toxic properties but also potential use as an alternative to nitrogen mustard anti-tumor drugs were studied and reported in a few publications thereafter $[15,19,20]$. St. Quintin et al. reported on the hydrolysis of Q observing six-membered ring sulfonium ions (Fig. 1f) as long-lived reaction intermediates in addition to the three-membered ring episulfonium ions known from SM (Fig. 1e) adding important insight into the behavior of $\mathrm{Q}$ in aqueous systems [21]. Analysis of $\mathrm{Q}$ and its hydrolysis and oxidation products from environmental samples by means of gas and liquid chromatography (LC) coupled to mass spectrometry (MS) has been described [22-26]. A method for the quantification of the urinary biotransformation products of Q using LC coupled to tandem mass spectrometry (MS/MS) was also published [27]. 
However, no methods describing protein biomarkers and their analysis have been presented so far.

We herein report on the adduct of Q formed with HSA upon reaction of the agent with the $\mathrm{Cys}^{34}$ residue of the protein. We further investigated the effect of adduct formation on the protein structure of HSA with a special focus on the local protein environment around $\mathrm{Cys}^{34}$ using molecular dynamics (MD) simulations as well as the potential role of six-membered ring sulfonium ions as reactive species. In analogy to the S-linked hydroxyethylthioethyl-adduct (HETE-HSA) found with SM as the reaction partner $[8,10]$, we refer to the adduct formed with Q as HETETE-HSA ("hydroxyethylthioethylthioethyl").

\section{Materials and methods}

\section{Chemicals and reagents}

Acetone (p.A.), acetonitrile (ACN, gradient grade), $\mathrm{CH}_{2} \mathrm{Cl}_{2}$ (for GC), isopropanol (iPrOH, p.A), water (LiChrosolv), and proteinase K (recombinant from Pichia pastoris, PCR grade) were purchased from Merck (Darmstadt, Germany); formic acid $(\mathrm{FA} \geq 98 \%)$ and $\mathrm{NaOCl}$ solution for decontamination $\left(12 \% \mathrm{Cl}_{2}\right)$ were from Carl Roth (Karlsruhe, Germany); pronase from Streptomyces griseus was from Roche (lot no. 70327222, Mannheim, Germany); $\mathrm{NH}_{4} \mathrm{HCO}_{3}$ (ultra-grade, $\geq$ 99.5\%) was from Fluka (Buchs, Switzerland); and three-fold deuterated atropine (Atr- $d_{3}$ ) was from CDN Isotopes (Pointe Claire, Quebec, Canada). Pooled human ethylenediaminetetraacetic acid (EDTA) plasma was purchased from Dunn Labortechnik (Asbach, Germany) and human EDTA plasma from different individuals was purchased from SonnenGesundheitszentrum (Munich, Germany). SM was made available by the German Ministry of Defence and tested for integrity and purity (99\%) in-house by NMR spectroscopy.

The Q hydrolysis product 1,2-bis(2-hydroxyethylthio) ethane and its partially deuterated form 1,2-bis(2hydroxyethylthio)- $d_{4}$-ethane have been synthesized by one of the authors during his tenure at the OPCW laboratory following methods from the scientific literature [28]. Both diols were chlorinated to yield Q and its partially deuterated variant in pure form (Fig. 1b and c). Molecular structure and purity (>95\%) were confirmed by ${ }^{1} \mathrm{H}$ - and ${ }^{13} \mathrm{C}-\mathrm{NMR}$ spectroscopy.

1,2-Bis(2-chloroethylthio)ethane: ${ }^{1} \mathrm{H}$-NMR $\left(\mathrm{CDCl}_{3}\right.$, $400 \mathrm{MHz}): \delta 2.81(\mathrm{~s}, 4 \mathrm{H}), 2.92(\mathrm{t}, 4 \mathrm{H}, J=6.61 \mathrm{~Hz}), 3.64(\mathrm{t}$, $4 \mathrm{H}, J=6.61 \mathrm{~Hz}) . \mathrm{C}\{\mathrm{H}\}$-NMR $\left(\mathrm{CDCl}_{3}, 100 \mathrm{MHz}\right): \delta 32.70$, 34.53, 43.07 .

1,2-Bis(2-chloroethylthio)- $d_{4}$-ethane: ${ }^{1} \mathrm{H}-\mathrm{NMR}\left(\mathrm{CDCl}_{3}\right.$, $400 \mathrm{MHz}): \delta 2.91(\mathrm{t}, 4 \mathrm{H}, J=6.52 \mathrm{~Hz}), 3.66(\mathrm{t}, 4 \mathrm{H}, J=$ $6.52 \mathrm{~Hz}) . \mathrm{C}\{\mathrm{H}\}-\mathrm{NMR}\left(\mathrm{CDCl}_{3}, 100 \mathrm{MHz}\right): \delta 32.68^{*}, 34.53$, 43.07.

* Signal intensity significantly reduced compared to the nondeuterated compound.
Stock solutions of SM and Q ( $150 \mathrm{mM}$ each) were prepared in $\mathrm{CH}_{2} \mathrm{Cl}_{2}$ and further diluted with iPrOH to yield working solutions $(5 \mathrm{mM})$.

Caution SM and $Q$ are potent vesicants and should only be handled by experienced and trained personnel using appropriate protective equipment in a properly working fume hood also requiring strict decontamination of all materials the poisons had contact to.

\section{Incubation of plasma with $\mathbf{Q}$ and $\mathrm{SM}$}

References of HSA-adducts formed with Q, Q- $d_{4}$, and SM were produced by mixing human EDTA plasma with the working solutions of the respective agent yielding $100 \mu \mathrm{M}$ each. Incubations were carried out for $2 \mathrm{~h}$ at $37^{\circ} \mathrm{C}$ and subsequently overnight at $4{ }^{\circ} \mathrm{C}$. Samples were stored at $-25^{\circ} \mathrm{C}$ until further processing.

\section{Plasma sample preparation for HETETE-CP and HETETE-CPF analysis}

Plasma samples $(50 \mu \mathrm{L})$ and blank plasma $(50 \mu \mathrm{L})$ were mixed with $250 \mu \mathrm{L}$ acetone for protein precipitation followed by rigorous vortexing and centrifugation $(3500 \mathrm{~g}, 3 \mathrm{~min}$ at room temperature, $\mathrm{RT}$ ). The protein pellet was washed with $250 \mu \mathrm{L}$ acetone supported by ultrasonication for $2 \mathrm{~min}$ and final centrifugation $(3500 \mathrm{~g}, 3 \mathrm{~min}, \mathrm{RT}$ ). The supernatant was discarded and the pellet air dried. Subsequently, $200 \mu \mathrm{L}$ $50 \mathrm{mM} \mathrm{NH} \mathrm{HCO}_{3}$ and $50 \mu \mathrm{L}$ pronase $(10 \mathrm{mg} / \mathrm{mL}$ in $50 \mathrm{mM} \mathrm{NH}_{4} \mathrm{HCO}_{3}$ to generate HETETE-CP) or $50 \mu \mathrm{L}$ proteinase $\mathrm{K}$ solution $\left(20 \mathrm{mg} / \mathrm{mL}\right.$ in $50 \mathrm{mM} \mathrm{NH}_{4} \mathrm{HCO}_{3}$ to generate HETETE-CPF) were added for dissolution and proteolysis $\left(2 \mathrm{~h}\right.$ at $\left.50^{\circ} \mathrm{C}\right)$. Afterwards, $750 \mu \mathrm{L} \mathrm{ACN}$ was added for protein precipitation and centrifugation $(13,000 \mathrm{~g}, 5 \mathrm{~min}, \mathrm{RT})$. The supernatant was dried under reduced pressure and redissolved in $250 \mu \mathrm{L} 50 \mathrm{mM} \mathrm{NH}_{4} \mathrm{HCO}_{3}$. A portion of $30 \mu \mathrm{L}$ was mixed with $60 \mu \mathrm{L}$ Atr- $d_{3}$ solution ( $3 \mathrm{ng} / \mathrm{mL}$ in $0.5 \% \mathrm{v} / \mathrm{v}$ FA) for micro liquid chromatography-electrospray ionization tandem-mass spectrometry working in the selected reaction monitoring mode ( $\mu$ LC-ESI MS/MS SRM).

\section{$\mu L C-E S I$ MS/MS (SRM) analysis}

Chromatography was carried out using a M5 microLC system comprising an integrated autosampler $\left(15^{\circ} \mathrm{C}\right)$ allowing $20 \mu \mathrm{L}$ sample volume injection (AB Sciex, Darmstadt, Germany). Peptides were separated at $60^{\circ} \mathrm{C}$ on an Acquity UPLC HSS T3 column $(50 \times 1.0 \mathrm{~mm}$ I.D., $1.8 \mu \mathrm{m}, 100 \AA$; Waters, Eschborn, Germany) protected by a precolumn (Security Guard Ultra cartridge C18 peptide; Phenomenex, Aschaffenburg, Germany) applying a binary gradient mobile phase with $30 \mu \mathrm{L} / \mathrm{min}$ of solvent A $(0.05 \% \mathrm{v} / \mathrm{v} \mathrm{FA})$ and 
solvent $\mathrm{B}\left(\mathrm{ACN} / \mathrm{H}_{2} \mathrm{O} 80: 20 \mathrm{v} / \mathrm{v}, 0.05 \% \mathrm{v} / \mathrm{v} \mathrm{FA}\right): t[\mathrm{~min}] / \mathrm{B}$ [\%]: $0 / 2,11 / 60,11.5 / 95,13.5 / 95,14 / 2,15 / 2$. Using an ESI interface working in positive mode $(5 \mathrm{kV})$ the QTrap $6500^{+}$ mass spectrometer (AB Sciex) was coupled to monitor product ions after collision-induced dissociation (CID) of analytes using nitrogen as collision gas. The following MS settings were applied: declustering potential (DP) $60 \mathrm{~V}$, curtain gas (CUR) 30 psi $\left(2.07 \times 10^{5} \mathrm{~Pa}\right)$, temperature $200{ }^{\circ} \mathrm{C}$, source gas 1 (GS1) 50 psi $\left(3.45 \times 10^{5} \mathrm{~Pa}\right)$, source gas $2(\mathrm{GS} 2)$ $60 \mathrm{psi}\left(4.14 \times 10^{5} \mathrm{~Pa}\right)$, entrance potential $(\mathrm{EP}) 10 \mathrm{~V}$, cell exit potential (CXP) $10 \mathrm{~V}$ each, and dwell time $50 \mathrm{~ms}$. The single protonated precursor ions of the biomarkers were fragmented with a collision energy $(\mathrm{CE})$ of $30 \mathrm{~V}$ to generate product ions by MS/MS working in the SRM mode: HETETE-CP: $\mathrm{m} / \mathrm{z}$ $383.1>\mathrm{m} / \mathrm{z}$ 105.0, $\mathrm{m} / \mathrm{z}$ 217.1; HETETE-CPF: $\mathrm{m} / \mathrm{z} 530.2>\mathrm{m} /$ $z$ 105.0, $\mathrm{m} / \mathrm{z}, 137.0$; HETE-CP: $\mathrm{m} / \mathrm{z}, 323.1>\mathrm{m} / \mathrm{z}, 105.0, \mathrm{~m} / \mathrm{z}$ 137.0; and HETE-CPF: $\mathrm{m} / \mathrm{z}, 470.2>\mathrm{m} / \mathrm{z}, 105.0, \mathrm{~m} / \mathrm{z}$ 137.0. The internal standard Atr- $d_{3}$ was monitored as follows: $\mathrm{m} / \mathrm{z}$ $293.3>m / z, 127.1$ and $m / z 93.1$ using a CE of $42 \mathrm{~V}$.

\section{$\mu L C-E S I$ MS/HR MS (Orbitrap) analysis}

Initial high-resolution tandem mass spectrometric (MS/HR MS) detection of HETETE-adducts was carried out to determine the exact masses of product ions. For chromatography of a $20-\mu \mathrm{L}$ sample volume, a MicroPro pump (Eldex Laboratories, Napa, CA, USA) in combination with an INTEGRITY autosampler and a MISTRAL column oven (both Spark Holland, Emmen, The Netherlands) was used. The stationary and mobile phases were the same as described above, but the gradient was as follows: $t[\mathrm{~min}] / \mathrm{B}[\%]: 0 / 10$; $11 / 60 ; 11.1 / 95 ; 13.9 / 95 ; 14 / 10 ; 15 / 10$. The system was controlled by the Eldex MicroPro 1.0.54 software (Eldex Laboratories) and coupled on-line to a QExactive plus Orbitrap mass spectrometer via the HESI II ion source (Thermo Scientific, Bremen, Germany). The following MS parameters were applied to monitor product ions of the single protonated precursor ions of HETETE-CP $(\mathrm{m} / \mathrm{z}, 383.1), d_{4^{-}}$ HETETE-CP $(\mathrm{m} / \mathrm{z}$ 387.1), HETETE-CPF $(\mathrm{m} / \mathrm{z}$ 530.2), and $d_{4}$-HETETE-CPF $(\mathrm{m} / z$ 534.2) in the parallel reaction monitoring (PRM) mode with a mass spectrometric resolution of 35,000 FWHM (full width at half maximum at $\mathrm{m} / z, 200$ ): sheath gas flow 23 arbitrary units (a.u.), aux gas flow 8 a.u., sweep gas flow 1 a.u., spray voltage $3.5 \mathrm{kV}$, capillary temperature $250{ }^{\circ} \mathrm{C}$, S-lens RF level 50 a.u., and aux gas heater temperature $125{ }^{\circ} \mathrm{C}$. Data were acquired between 3 and $15 \mathrm{~min}$. The maximum automated gain control value (AGC) was set to $2 \times 10^{5}$ charges in the Orbitrap analyzer, the maximum injection time (IT) to $100 \mathrm{~ms}$, the isolation window to $2.0 \mathrm{~m} / \mathrm{z}$, the isolation offset to $0.5 \mathrm{~m} / \mathrm{z}$, and a fixed first mass to $50.0 \mathrm{~m} / \mathrm{z}$. For all analytes, a normalized collision energy (NCE, normalized to $m / z, 200, z=1$ ) of $25 \mathrm{~V}$ was applied. The MS system was controlled by the Excalibur 4.1 software
(Thermo Scientific), and for data processing, the FreeStyle 1.3 software was used (Thermo Scientific).

\section{Selectivity}

The selectivity of HETETE-CP and HETETE-CPF detection in plasma samples was investigated by $\mu \mathrm{LC}$-ESI MS/MS (SRM) analysis of blank plasma (not exposed to any agent) from 6 individuals following the standard protocol for interference detection.

\section{Determination of linear range and lower limit of identification}

To determine the linearity of HETETE-CP and HETETE-CPF peak areas plotted against the concentration of the agent applied for incubation with plasma and to estimate the respective lower limits of identification (LOI), 12 plasma standards were produced. Accordingly, the working solution of $\mathrm{Q}$ was diluted in $\mathrm{iPrOH}$ yielding 12 differently concentrated solutions. An aliquot of $20 \mu \mathrm{L}$ was added to $1980 \mu \mathrm{L}$ plasma each $(n=3)$ resulting in Q concentrations of $50 \mu \mathrm{M}, 20 \mu \mathrm{M}, 4 \mu \mathrm{M}$, $800 \mathrm{nM}, 400 \mathrm{nM}, 160 \mathrm{nM}, 80 \mathrm{nM}, 32 \mathrm{nM}, 16 \mathrm{nM}, 6.4 \mathrm{nM}$, $3.2 \mathrm{nM}$, and $1.28 \mathrm{nM}$. Samples were incubated in triplicate, prepared, and analyzed by $\mu$ LC-ESI MS/MS (SRM) as described above. The LOI was defined as the lowest concentration of the spiked agent still allowing detection of the adduct in all three replicates exhibiting the respective ion ratios of product ions obtained from a reference sample $(50 \mu \mathrm{M} \mathrm{Q}$ in plasma).

\section{Stability of HETETE-CP and HETETE-CPF in the autosampler}

The stability of both peptide-adducts present in the prepared plasma samples stored at $15^{\circ} \mathrm{C}$ in the autosampler was determined hourly by $\mu \mathrm{LC}$-ESI MS/MS (SRM) analysis over a 24$\mathrm{h}$ period. Peak areas obtained from the extracted ion chromatograms (XIC) of the most intense product ions $(\mathrm{m} / \mathrm{z}$ 105.0 each) were used to follow the relative concentrationtime profiles.

\section{Freeze and thaw cycles}

Plasma was incubated with $\mathrm{Q}$ as described above in concentrations of $50 \mu \mathrm{M}$ and $20 \mu \mathrm{M}$. Three aliquots $(500 \mu \mathrm{L}$ each) of both mixtures were pipetted into separate reaction vials, and $50 \mu \mathrm{L}$ each was analyzed immediately (day $0, n=3$ ) by $\mu \mathrm{LC}$ ESI MS/MS (SRM) to monitor HETETE-CP following the standard protocol. The remaining volumes were frozen and stored at $-20{ }^{\circ} \mathrm{C}$ for $24 \mathrm{~h}$ prior to thawing and repeated analysis (day $1, n=3$ ). This cycle of freezing and thawing was repeated three times (day 2 and day $3, n=3$, each). Peak areas 
obtained from XICs $(m / z, 105.0)$ were determined to follow the relative concentrations of HETETE-CP as a measure of HETETE-HSA stability.

\section{Co-incubation to characterize the relative reactivity of $Q$ and SM}

Buffered HSA solutions $(960 \mu \mathrm{L}, 133 \mu \mathrm{g} / \mathrm{mL}$ in PBS, $1.96 \mu \mathrm{M}$ ) were incubated in ultrafiltration (UF) devices $(0.5 \mathrm{~mL}$ Amicon ultrafiltration unit, molecular weight cutoff $10 \mathrm{kDa}$, Merck-Millipore, Darmstadt, Germany) with (i) $100 \mu \mathrm{M}$ SM, (ii) $100 \mu \mathrm{M}$ Q, (iii) $100 \mu \mathrm{M}$ SM plus $100 \mu \mathrm{M}$ $\mathrm{Q}$, and (iv) $100 \mu \mathrm{M}$ SM plus $10 \mu \mathrm{M}$ Q for $2 \mathrm{~h}$ at $37^{\circ} \mathrm{C}$. Aliquots of $100 \mu \mathrm{L}$ were mixed with $300 \mu \mathrm{L} 50 \mathrm{mM}$ $\mathrm{NH}_{4} \mathrm{HCO}_{3}$ and $100 \mu \mathrm{L}$ pronase solution $(10 \mathrm{mg} / \mathrm{mL}$ in $50 \mathrm{mM} \mathrm{NH}_{4} \mathrm{HCO}_{3}$ ) carried out in triplicate. Following proteolysis for $2 \mathrm{~h}$ at $37^{\circ} \mathrm{C}$, samples were subjected to UF (10 min at $\left.12,070 \mathrm{~g}, 15^{\circ} \mathrm{C}\right)$ and portions of the filtrates $(30 \mu \mathrm{L})$ were diluted 1:3 with Atr- $d_{3}$ solution ( $3 \mathrm{ng} / \mathrm{mL}$ in $0.5 \% \mathrm{v} / \mathrm{v} \mathrm{FA}$ ) prior to $\mu \mathrm{LC}$-ESI MS/MS (SRM) analysis. Peak areas of the XICs of the product ions at $\mathrm{m} / \mathrm{z} 105.0$ were determined as a measure of HETE-CP and HETETE-CP for relative quantification of the respective HSA-adducts.

\section{MD simulations}

MD simulations were carried out using the GROMACS package [29] (v. 2020.2) employing the GROMOS96 53A7 force field [30]. The topology for cysteine adducted by Q (HETETE-Cys ${ }^{34}$ ) was created using the Automated Topology Builder (ATB) version 3.0 [31], and the resulting values (ATB Molecule ID 478917) were used to add the modified amino acid to the force field. Coordinates for HSA were obtained from the protein database (PDB entry: 1AO6) and used for the simulation of the apo protein. The starting structure for the construction of the HETETE-Cys ${ }^{34}$ variant of HSA was extracted from the production simulation (200 ns) of apo HSA and a frame was chosen in which $\mathrm{Cys}^{34}$ is solvent accessible and the HETETE moiety could be constructed without steric hindrance of neighboring residues. The $\mathrm{Cys}^{34}$ residue of HSA was modified using UCSF Chimera [32] so that the HETETE moiety points either into the solvent or fits into the groove between the two helices adjacent to $\mathrm{Cys}^{34}$. Apo HSA and variants were centered in a cubic unit cell with a distance between solute and box edge of $1.0 \mathrm{~nm}$ that was subsequently filled with simple point charge (SPC) water [33]. Fourteen sodium ions were added to balance the charge. Steepest descent minimization was performed, followed by 200 ps of canonical (NVT) equilibration and 200 ps of equilibration under an isothermal-isobaric (NPT) ensemble. Production simulations of $200 \mathrm{~ns}$ for apo HSA and $100 \mathrm{~ns}$ for the two HETETE-Cys ${ }^{34}$ variants followed. Positional restraints were applied to the protein during equilibration and released for the production run. All bond lengths were constrained using the LINCS method, allowing a 2 -fs time step [34]. The Verlet cutoff scheme was applied [35]. Longrange electrostatic interactions were calculated with the particle mesh Ewald (PME) method [36, 37]. Simulations utilized the velocity-rescaling thermostat [38] and Parrinello-Rahman barostat $[39,40]$. Further details can be found in the Electronic supplementary material (ESM).

\section{Results and discussion}

The analysis of biomedical samples for possible exposure to SM is well established. While biotransformation products in urine are only present for a few days after exposure, protein-adducts can often be detected for several weeks [4]. Therefore, protein-adducts of SM are generally considered the most valuable biomarkers. As there are currently no established protein biomarkers of exposure to $\mathrm{Q}$, a person exposed to this agent will show the typical clinical signs and symptoms of SM injury, but the biomedical analysis will turn out negative. Also, the coexposure to $\mathrm{SM}$ and $\mathrm{Q}$ due to the presence of $\mathrm{Q}$ as a minor component of the mustard preparations will remain undetected. Therefore, protein biomarkers for exposure to $\mathrm{Q}$ must be identified and analytical procedures must be established following internationally accepted quality standards.

The OPCW tests laboratory capabilities through BioPTs. The regulations applicable for the reporting of data in these BioPTs also apply when reporting data from real samples collected on missions [41]. Positive identification of an agent is usually achieved through reporting of at least two different biomarkers where every biomarker is identified by an individual analytical method. Markers are divided into primary and secondary ones. While secondary markers are not unambiguous for identification but able to support identifications based on primary ones, data has to be reported from at least one primary biomarker. For the identification of SM in human plasma samples, the primary biomarkers are HETE-CP (from HSA), HETE-CPF (from HSA), N1/N3-HETE-His (from HSA and Globin), and other protein- or amino acid-adducts (e.g., $\mathrm{AE}^{230}$ (-HETE) VSKL from HSA [12] and $\mathrm{LGM}^{329}$ (-HETE) F from HSA, [9]), while the secondary marker for SM is thiodiglycol [41]. Our aim was to develop methods for the analysis and identification of HETETE-CP and HETETE-CPF as primary biomarkers of $\mathrm{Q}$ in plasma. Analysis of these two peptides will be sufficient to identify the spiking chemical $\mathrm{Q}$ in OPCW BioPTs and therefore also for the identification of exposure to $\mathrm{Q}$ in real samples. Accordingly, the formation of Q-adducts in plasma corresponding to those known from SM had to be detected and identified. 


\section{Identification of HETETE-CP and HETETE-CPF by MS/HR MS}

HETETE-CP and HETETE-CPF were identified based on MS/HR MS spectra extracted from chromatographic separation. Product ion spectra of both protonated biomarker precursor ions (HETETE-CP $\mathrm{m} / \mathrm{z} 383.1$ and HETETE-CPF $\mathrm{m} / \mathrm{z}$ 530.2) are shown in Fig. 2 and the structural assignment of the signals is summarized in Table 1 for HETETE-CP. Assignments for HETETE-CPF can be found in the ESM (Table S1).

Characteristic predominant ions of HETETE-CP were found at $\mathrm{m} / z$ 105.0371 representing the HETE moiety and at $\mathrm{m} / \mathrm{z} 137.0087$ corresponding to the HETE moiety with the adjacent sulfur atom (Table 1). The specific product ion consisting of the dipeptide CP was found at $\mathrm{m} / \mathrm{z} 217.0637$ even though present in lower intensity (Fig. 2a). The CID of HETETE-CPF also yielded signals at about $\mathrm{m} / \mathrm{z} .105 .0$ and $\mathrm{m} / \mathrm{z}$
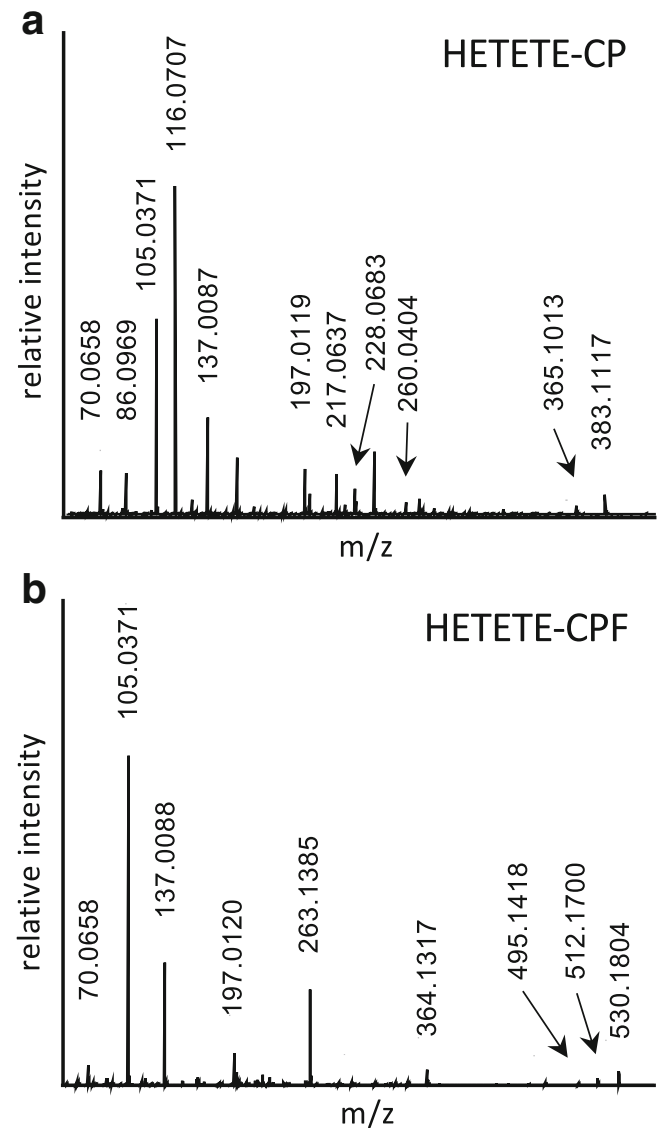

Fig. 2 High-resolution product ion spectra of the alkylated di- and tripeptide biomarkers: a HETETE-CP, $[\mathrm{M}+\mathrm{H}]^{+} \mathrm{m} / \mathrm{z}, 383.117$ and b HETETE-CPF, $[\mathrm{M}+\mathrm{H}]^{+} \mathrm{m} / z$, 530.1804. Spectra were extracted from $\mu$ LC-ESI MS/HR MS (Orbitrap) analysis of HETETE-HSA-adducts after proteolysis with pronase (HETETE-CP) and proteinase K (HETETE$\mathrm{CPF}$ ). These references were produced by incubation of plasma with $\mathrm{Q}$ $(50 \mu \mathrm{M})$. Labeled signals were assigned to product ions of the single protonated biomarkers as summarized in Table 1 and ESM Table S1
137.0 indicating the presence of the HETETE moiety. In addition, product ions at $\mathrm{m} / \mathrm{z} 263.1385$ and $\mathrm{m} / \mathrm{z} 364.1317$ found with high intensity were derived from the peptide backbone of the biomarker and thus also confirmed the identity of HETETE-CPF. Interestingly, the agent-related product ions at $\mathrm{m} / \mathrm{z} 105.0$ and $\mathrm{m} / \mathrm{z} 137.0$ have also been reported before to be generated by CID of HETE-CP [7, 13] and HETE-CPF [10] representing the same chemical structures. Comparable product ions derived from similar cleavage sites of the thioalkyl chain that represent the entire HETETE moiety either with $(\mathrm{m} / \mathrm{z}$ 197.0119) or without $(\mathrm{m} / \mathrm{z}, 165.0400)$ the $\mathrm{S} \gamma$ of $\mathrm{Cys}^{34}$ were only detected with minor intensity (Fig. 2) not well suited for their use in $\mu \mathrm{LC}$-ESI MS/MS (SRM) monitoring. The intensity of the product ion of HETETE-CP at $\mathrm{m} / \mathrm{z}$ 116.0707 (Fig. 2a) was found to be influenced by interferences derived from the sample matrix despite exact mass determination and was therefore not appropriate for compound detection with optimal selectivity. Signals referred to above were assigned with a mass deviation typically not exceeding 3 ppm (Table 1, ESM Table S1), thus proving highest confidence for biomarker identification. Therefore, for optimum sensitivity and selectivity, the transitions to $\mathrm{m} / \mathrm{z}, 105.0$ were chosen for both biomarkers in $\mu$ LC-ESI MS/MS (SRM) analysis in addition to $m / z 217.1$ for HETETE-CP and to $m / z 137.0$ for HETETE-CPF. For the most sensitive detection of the product ions, a modern triple quadrupole mass spectrometer was used promising optimal sensitivity.

\section{Selectivity of $\mu$ LC-ESI MS/MS (SRM) analysis}

Investigation of blank plasma from 6 individuals revealed that optimal detection of HETETE-CP was possible without any interferences when using the product ions at $\mathrm{m} / \mathrm{z} 105.0$ and $\mathrm{m} / \mathrm{z}$ 217.1. Optimum monitoring of HETETE-CPF not showing any interferences was achieved using the transitions to $\mathrm{m} / \mathrm{z}$ 105.0 and $\mathrm{m} / \mathrm{z} 137.0$ Therefore, product ions mentioned above were chosen to set up the verification method simultaneously detecting the alkylated di- and tripeptide. XICs of a blank plasma sample are shown in Fig. 3a and dillustrating the most intense product ion at $\mathrm{m} / \mathrm{z}$ 105.0, each.

\section{Linear range and LOI}

To characterize the $\mathrm{Q}$ concentration-dependent amount of the HETETE-Cys ${ }^{34}$-adduct of HSA, plasma was spiked with rising concentrations of Q to determine the HETETE-CP and HETETE-CPF peak areas obtained from the XICs of their product ions at $\mathrm{m} / \mathrm{z} 105.0$, each. The dipeptide-adduct $(\log \mathrm{P}$ -1.8593 ) was detected at $t_{\mathrm{R}} 5.4 \mathrm{~min}$ and the tripeptide-adduct $(\log \mathrm{P}-1.2455)$ at $t_{\mathrm{R}} 7.8 \mathrm{~min}$ corresponding to the higher hydrophobicity of HETETE-CPF. In both cases, linearity was found from $1.3 \mathrm{nM}$ to $50 \mu \mathrm{M}\left(r^{2}>0.996\right)$ indicating dose-dependent adduct formation as well as reliable sample 
Table 1 Product ions of single protonated HETETE-CP
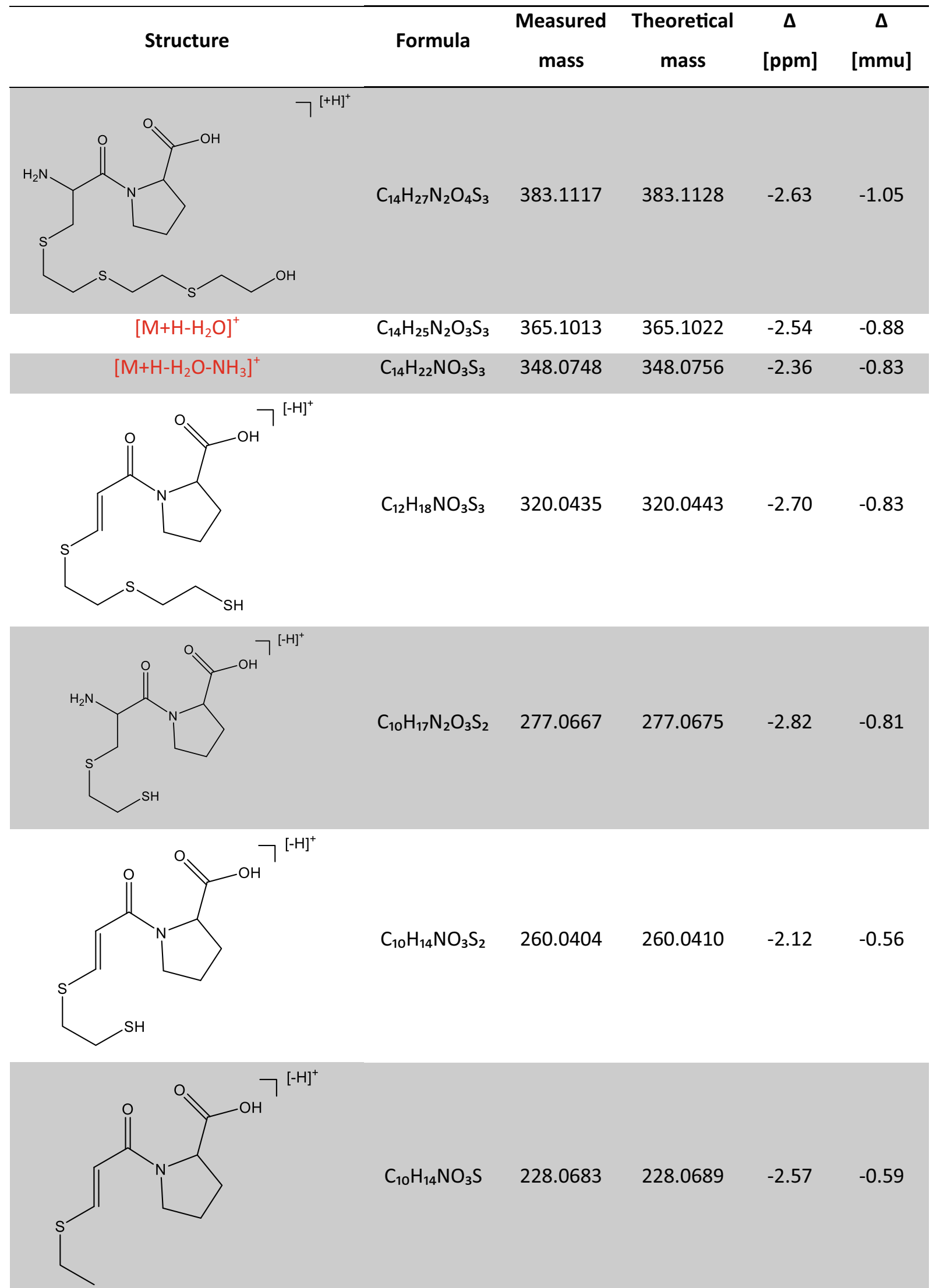

$\mathrm{C}_{10} \mathrm{H}_{14} \mathrm{NO}_{3} \mathrm{~S} \quad 228.0683 \quad 228.0689 \quad-2.57 \quad-0.59$ 
Table 1 (continued)

$$
\begin{array}{llllll} 
& 217.0641 & -2.13 & -0.44
\end{array}
$$
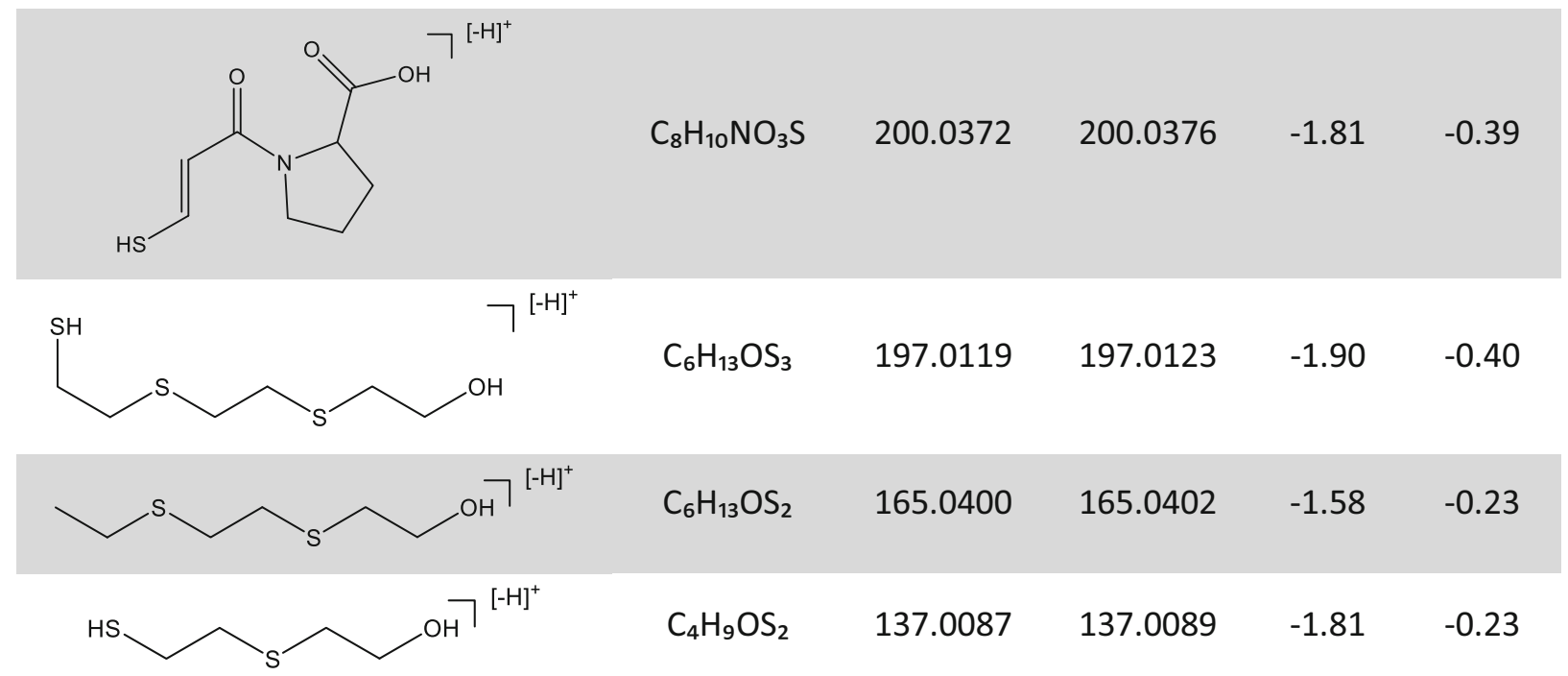

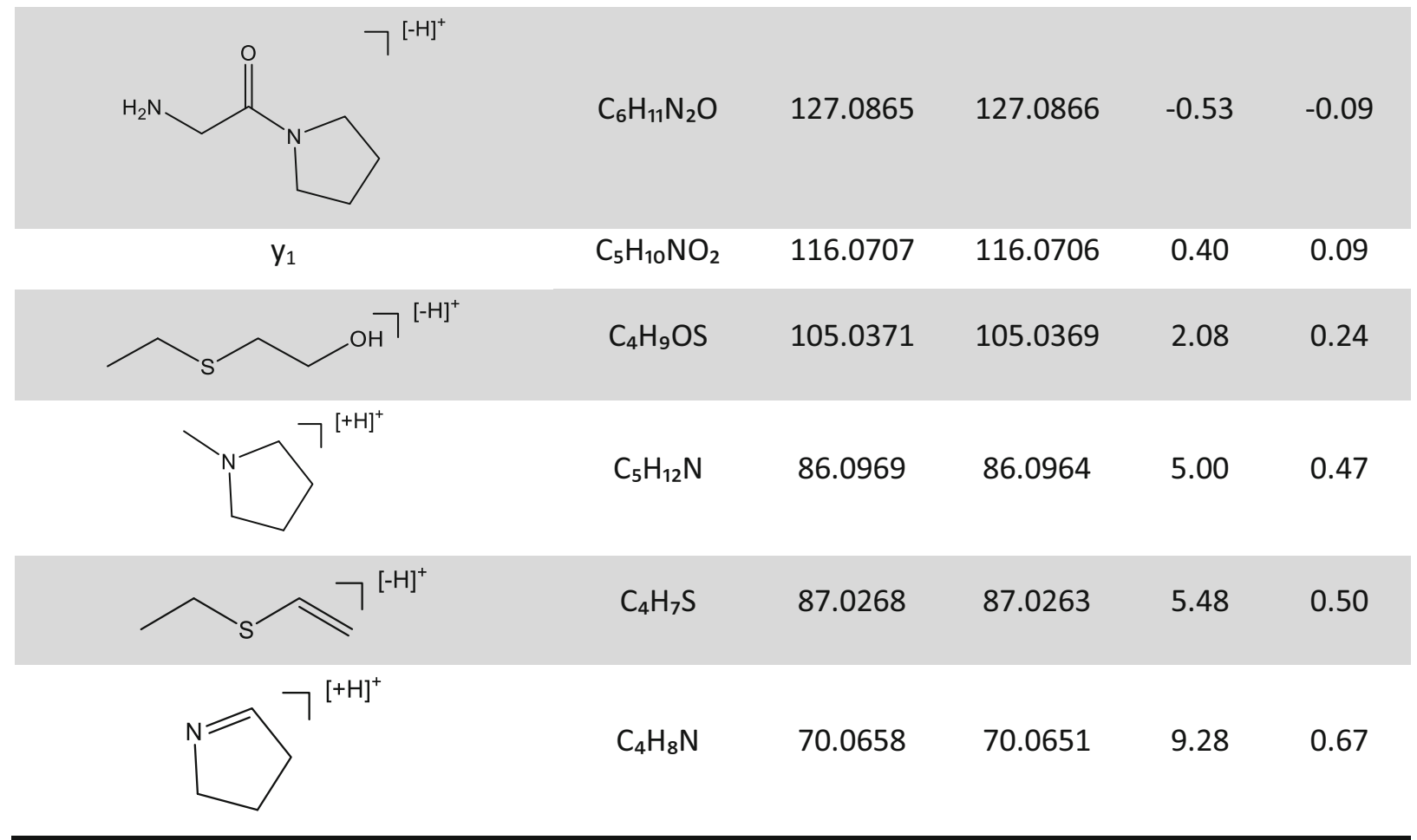

Data was extracted from a $\mu$ LC-ESI MS/HR MS (Orbitrap) run of HETETE-HSA-adducts after proteolysis with pronase. This reference was produced by incubation of plasma with Q $(50 \mu \mathrm{M})$. The corresponding product ion spectrum is shown in Fig. 2a. Mass calculation was done using the FreeStyle 1.3 software (Thermo Fisher). Structures represent one possible isomer each 
preparation procedures. The ion ratios of the diverse product ions (given in percentage) were calculated from the peak area (A) ratio of the relevant XICs, e.g., $100 \times A(\mathrm{~m} / \mathrm{z}, 137.0) / \mathrm{A}(\mathrm{m} / \mathrm{z}$ 105.0) abbreviated as (137/105). The following ion ratios were found for these transitions: HETETE-CP (217/105) $50.1 \%$ and HETETE-CPF (137/105) 53.3\%. According to the OPCW quality criteria, ion ratios from biomarkers of any sample had to fit those of a reference for unambiguous identification. The LOI was defined as the lowest concentration of Q still fulfilling this criterion. Accordingly, the LOI for HETETE-CP detection was found at $32 \mathrm{nM}$ Q in plasma, whereas $6.4 \mathrm{nM}$ was found for HETETE-CPF. XICs $(\mathrm{m} / \mathrm{z}$ 105.0) corresponding to these LOI concentrations are illustrated in Fig. $3 b$ and e. These LOI are in the same range as those of the corresponding HSA-adducts of SM HETE-CP (156 nM and $19.5 \mathrm{nM}$ [13]) and HETE-CPF (10 nM [10]). However, such limits strictly depend on the method-specific sample preparation procedures with respect to concentrating and diluting working steps as well as to instruments used in terms of injected sample amount, ion yield (sensitivity), and mass resolution (selectivity). Therefore, the mentioned LOI were quite similar for all vesicant biomarkers.

\section{Stability in the autosampler}

HETETE-CP as well as HETETE-CPF were found to be of sufficient stability in the prepared samples when stored at $15{ }^{\circ} \mathrm{C}$ in the autosampler (results not shown). Only a slight peak area decrease of less than $7 \%$ for both biomarkers indicated a negligible concentration decrease within the $24-\mathrm{h}$ test period thus documenting good stability beneficial especially when large sets of samples have to be analyzed.

\section{Freeze and thaw cycles}

No degradation of HETETE-HSA in frozen and thawed plasma was determined by monitoring the HETETE-CP biomarker (data not shown), thus documenting that plasma samples can be handled following common rules of plasma sample treatment without the need for special care.

\section{Co-incubation to characterize the relative reactivity of $\mathrm{SM}$ and $\mathrm{Q}$ for $\mathrm{Cys}^{34}$ alkylation}

The co-incubation experiment was carried out to investigate the relative reactivity of SM and Q toward alkylation of $\mathrm{Cys}^{34}$ in HSA. Q and SM competed for the thiol groups of a limited amount of $\mathrm{Cys}^{34}$ applied as neat HSA instead of plasma to minimize any side reactions with other plasma proteins. As numerous amino acids of HSA are expected to be prone to alkylation as exemplarily shown for $\mathrm{Glu}^{230}$ [12] and $\mathrm{Met}^{329}$ [9], a low HSA concentration was applied. After incubation, samples were subjected to pronase-mediated proteolysis to monitor HETE-CP and HETETE-CP simultaneously as measures of their respective HSA-adducts. For comparison, the maximum peak areas of both biomarkers resulting from single incubation $(100 \mu \mathrm{M}$ each) were determined. These values served as a maximum reference $(100 \%)$ to determine any effective competition that would result in reduced areas. Accordingly, under the assumption of the same alkylating reactivity of SM and Q toward $\mathrm{Cys}^{34}$, a decrease to $50 \%$ of
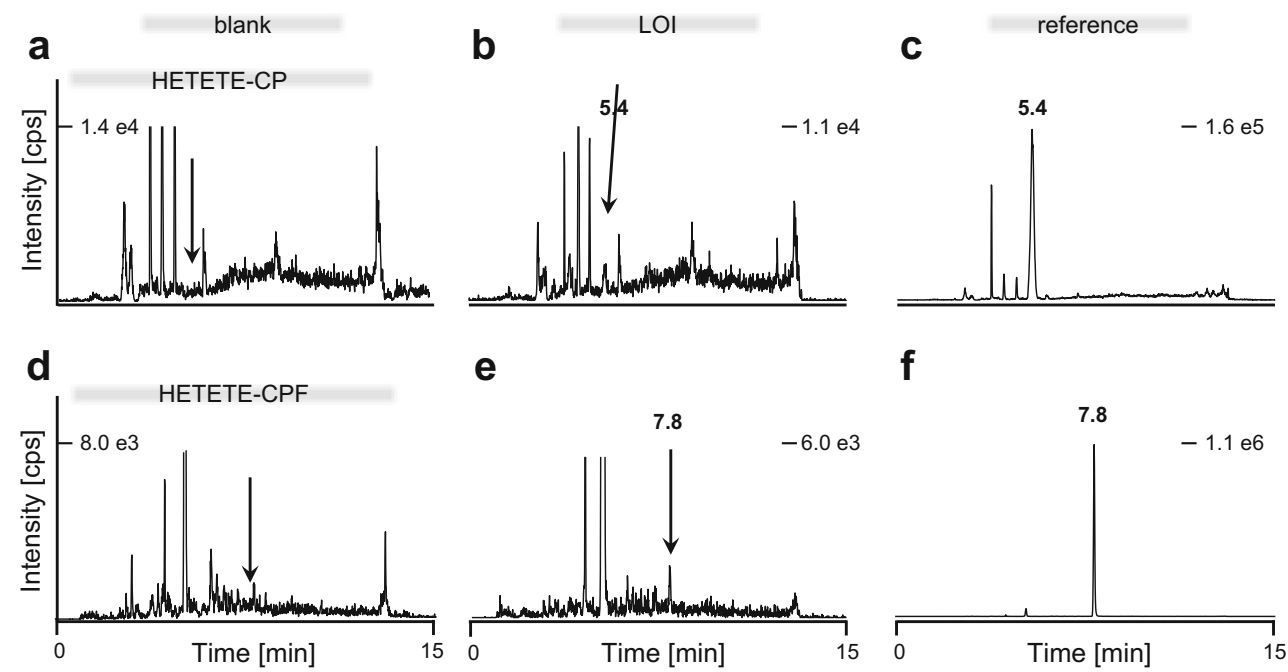

e

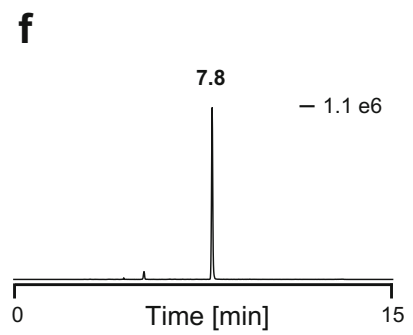

Fig. 3 Detection of the alkylated di- and tripeptide biomarkers of $\mathrm{Q}$ exposure in human plasma. HETETE-CP: a blank, b plasma incubated with Q (32 nM) corresponding to the lower limit of identification (LOI), and $\mathbf{c}$ reference sample produced after plasma incubation with $100 \mu \mathrm{M}$ Q. The alkylated dipeptide was produced by pronase cleavage of adducted HSA in plasma. HETETE-CPF: d blank, e plasma incubated with Q
$(6.4 \mathrm{nM})$ corresponding to the LOI, and $\mathbf{f}$ reference sample produced after plasma incubation with $50 \mu \mathrm{M}$ Q. The alkylated tripeptide was produced by proteinase K cleavage of adducted HSA in plasma. All analyses were performed as $\mu \mathrm{LC}$-ESI MS/MS runs in the selected reaction monitoring mode. For reasons of clarity, only the traces of the product ion at $\mathrm{m} / \mathrm{z}$ 105.0 are illustrated for both biomarkers 
the reference level would be expected for both biomarkers when incubating with a 1:1-M ratio.

When using $19.6 \mu \mathrm{M}$ HSA, individual peak areas resulting from co-incubation with $100 \mu \mathrm{M} \mathrm{SM}$ and $100 \mu \mathrm{M}$ Q were identical to those from separate incubation, thus documenting no competition. This was most likely due to a large extent of additional reactions including simple hydrolysis as well as amino acid alkylations indicating the high reactivity of both vesicants. Therefore, we repeated the incubations using a HSA concentration of $1.96 \mu \mathrm{M}$. This is equal to the maximum concentration of free $\mathrm{Cys}^{34}$ and was chosen to ensure an effective molar excess of the vesicants when applied at $100 \mu \mathrm{M}$ concentrations. Results are shown in Table 2.

Resulting reference values of peak areas from triplicate measurements of HETE-CP and HETETE-CP, after individual incubations with $100 \mu \mathrm{M}$ of SM and Q, respectively, were identical (about $4.85 \times 10^{5} \mathrm{cts} \pm 6 \%$, each) thus supporting the idea of an identical molar yield (identical extent of $\mathrm{Cys}^{34}$ alkylation). After co-incubation $(100 \mu \mathrm{M}$ of SM and $100 \mu \mathrm{M}$ of Q), a reasonably higher yield of HETETE-CP ( $79 \pm 3 \%$ of the reference) was found, whereas only $59 \pm 3 \%$ of the reference was detected for HETE-CP, thus indicating a higher reactivity of $\mathrm{Q}$. The same effect was observed after coincubation with $100 \mu \mathrm{M} \mathrm{SM}$ and $10 \mu \mathrm{M}$ Q yielding only $79 \pm$ $1 \%$ of the HETE-CP and $12 \pm 4 \%$ of the HETETE-CP reference. This relative concentration of both vesicants $(10: 1)$ was chosen to simulate ratios known from mustard ammunitions [17]. The higher total yield of alkylated CP (sum of HETE-CP and HETETE-CP $>100 \%$ when co-incubating with $100 \mu \mathrm{M}$ each) was presumably due to the higher total vesicant concentration $(200 \mu \mathrm{M}$ instead of $100 \mu \mathrm{M}$ in single incubation) increasing the product concentration according to the law of mass action.

In summary, Q appears somewhat more reactive than SM (factor 1.33) for $\mathrm{Cys}^{34}$ alkylation. This might presumably be due to, e.g., a higher affinity of $\mathrm{Q}$ to amino acids close to $\mathrm{Cys}^{34}$ resulting in a favorable binding complex or a more precise orientation of the reactive sulfonium ion in a "nearattack" conformation, a higher intrinsic reactivity of the Q sulfonium ion compared to the one of SM, or a smaller extent of side reactions. The important conclusion of our data, however, supports the observation that HETETE-HSA will be produced even though it might be present in much smaller concentrations than SM. This is of high relevance for the possibility of biomarker detection when $\mathrm{Q}$ is only found as an impurity or side-product in a mustard mixture.

\section{Analysis of apo HSA and HETETE-Cys ${ }^{34}$ variants using MD simulations}

As the most abundant protein in human plasma and its importance as a drug carrier and binding partner for many endogenous molecules [42], HSA has been subject to intensive studies using MD simulations [43, 44]. This is also true for the investigation of the role of $\mathrm{Cys}^{34}$ that represents the largest pool of free thiol groups in human plasma and shows an unusually low $\mathrm{p} K_{\mathrm{a}}$ of 8.2 [45-47]. It was shown that relatively long simulation times (around $1 \mu \mathrm{s}$ ) are required for adequate structural sampling, but as we are mainly interested in the changes in the local protein environment around $\mathrm{Cys}^{34}$, simulation times of $200 \mathrm{~ns}$ for apo HSA and $100 \mathrm{~ns}$ for the HETETE-adduct were considered appropriate. Previous MD studies have shown that $\mathrm{Cys}^{34}$ is only partially solvent accessible and forms a strong hydrogen bond with $\mathrm{Tyr}^{84}$ [46]. In the 200-ns simulation of apo HSA, in which the backbone root mean square deviation (RMSD) value stabilizes after around $80 \mathrm{~ns}$, we observed the same phenomenon. Nevertheless, it was also possible to observe and extract various simulation frames in which the $\mathrm{S} \gamma$ of $\mathrm{Cys}^{34}$ is solvent accessible. We used one such simulation frame to construct the HETETEadduct in two variants: one with the HETETE moiety pointing into the solvent and one with the HETETE moiety fitting into the groove formed by the two helices adjacent to $\mathrm{Cys}^{34}$. The simulation of the "in groove" variant showed a stable backbone RMSD value after about 35 ns and the "in solvent" variant after around $60 \mathrm{~ns}$ out of a total of $100 \mathrm{~ns}$ simulation time, each. HSA consists of three structurally similar domains (I, II, and III) and each of them is formed by two subdomains (A and B) [48]. Cys ${ }^{34}$ is located in subdomain IA (residues 5-107) (Fig. 4). Other HSA amino acid residues potentially subject to alkylation by SM and

Table 2 Co-incubation to characterize the relative reactivity of SM and Q for Cys ${ }^{34}$ alkylation

\begin{tabular}{lccc}
\hline Agent incubated and concentration & Relative peak area of HETE-CP [\%] & Relative peak area of HETETE-CP [\%] & Total of relative peak areas [\%] \\
\hline SM, $100 \mu \mathrm{M}$ & 100 & 0 & 100 \\
$\mathrm{Q}, 100 \mu \mathrm{M}$ & 0 & 100 & 100 \\
$\mathrm{SM}, 100 \mu \mathrm{M}+\mathrm{Q}, 100 \mu \mathrm{M}$ & $59 \pm 3$ & $79 \pm 3$ & $138 \pm 6$ \\
$\mathrm{SM}, 100 \mu \mathrm{M}+\mathrm{Q}, 10 \mu \mathrm{M}$ & $79 \pm 0$ & $12 \pm 4$ & $91 \pm 4$
\end{tabular}

Relative peak areas were calculated from extracted ion chromatograms of the product ion at $m / z$. 105.0. Incubations were carried out in triplicate each HETE-CP HSA-derived biomarker obtained after pronase-catalyzed proteolysis of the adduct of HSA and SM, HETETE-CP HSA-derived biomarker obtained after pronase-catalyzed proteolysis of the adduct of HSA and Q, SM sulfur mustard, $Q$ sesquimustard 


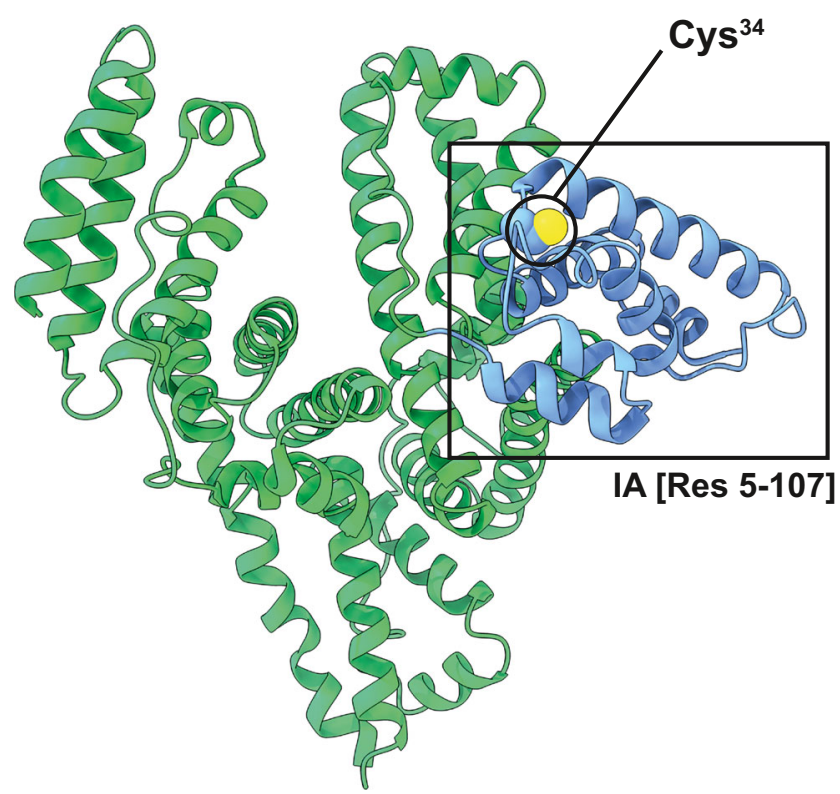

Fig. 4 Protein structure of apo HSA (PDB: 1AO6) subdomain IA is highlighted in light blue comprising the $\mathrm{Cys}^{34}$ residue that is prone to alkylation by SM and Q resulting in HETE-Cys ${ }^{34}$ - and HETETE-Cys ${ }^{34}$ adducts, respectively

$\mathrm{Q}\left(\mathrm{E}^{230}, \mathrm{M}^{329}\right)$ are all solvent exposed without the sterical constraints of $\mathrm{Cys}^{34}$.

Visual inspection of the two MD trajectories of the HETETE-adduct and comparison with the apo protein did not yield significant differences in the structure of subdomain IA. The two different "in solvent" and "in groove" starting structures did not result in markedly different trajectories. In all simulations, subdomain IA remained rather rigid with small root mean square fluctuation (RMSF) values per residue compared to other parts of the protein (see ESM Figs. S1-S3).

We observed that the HETETE moiety of the adducted $\mathrm{Cys}^{34}$ showed high flexibility and conformational mobility as expected due to the large number of rotatable bonds. This flexibility was, however, steered and restricted by the two helices adjacent to $\mathrm{Cys}^{34}$. The HETETE moiety starting at the $\mathrm{S} \gamma$ of $\mathrm{Cys}^{34}$ moved toward the protein surface while showing an important hydrophobic interaction with the side chain of $\mathrm{Leu}^{42}$, that is in almost constant van der Waals contact (average distance $3.8 \AA$ ) with the HETETE moiety. The polar end of the HETETE moiety with the terminal hydroxyl group was found to regularly explore the solvent, but for most of the simulation time, it acted as either a hydrogen donor or acceptor interacting with nearby amino acid residues (as $\mathrm{H}$ donor: $\mathrm{Asp}^{38}$, $\mathrm{Lys}^{41}, \mathrm{Glu}^{45}, \mathrm{Lys}^{73}, \mathrm{Thr}^{76}, \mathrm{Val}^{77}$, $\mathrm{Leu}^{80}$; as $\mathrm{H}$ acceptor: $\mathrm{Lys}^{41}, \mathrm{Lys}^{73}, \mathrm{Leu}^{80}, \mathrm{Arg}^{81}$ ). By far, the most important of these hydrogen bonding partners are the $\mathrm{Glu}^{45}$ carboxyl group and the Lys ${ }^{41}$ amino group. The HETETE hydroxyl group forms a hydrogen bond most often with $\mathrm{Glu}^{45}$. The Lys ${ }^{41}$ residue is the second most preferred hydrogen bonding partner apart from the solvent.
This observation is also reinforced by cluster analysis employing the method of Daura [49] on those parts of the MD trajectories showing stable backbone RMSD values to reduce the dimensionality of the trajectories containing 10,000 frames each (Fig. 5). The most populated cluster $(56 \%$ of frames, Fig. 5a cluster 1) shows hydrogen bonding with $\mathrm{Glu}^{45}$ and hydrophobic interactions with $\mathrm{Lys}^{41}$ and $\mathrm{Leu}^{42}$. Despite the polar amino group, the four methylene groups in the $\mathrm{Lys}^{41}$ side chain can contribute significantly to hydrophobic interactions as well [50]. The second most populated cluster ( $27 \%$ of frames, Fig. 5b cluster 2) shows hydrogen bonding with the terminal amino group of Lys ${ }^{45}$, while the third most populated cluster $(5 \%$ of frames, Fig. $5 \mathrm{c}$ cluster 3) shows again hydrogen bonding with $\mathrm{Glu}^{45}$ and hydrophobic "guidance" by $\mathrm{Lys}^{41}$ and $\mathrm{Leu}^{42}$. This is in agreement with the hydrogen bonding analysis described above.

a

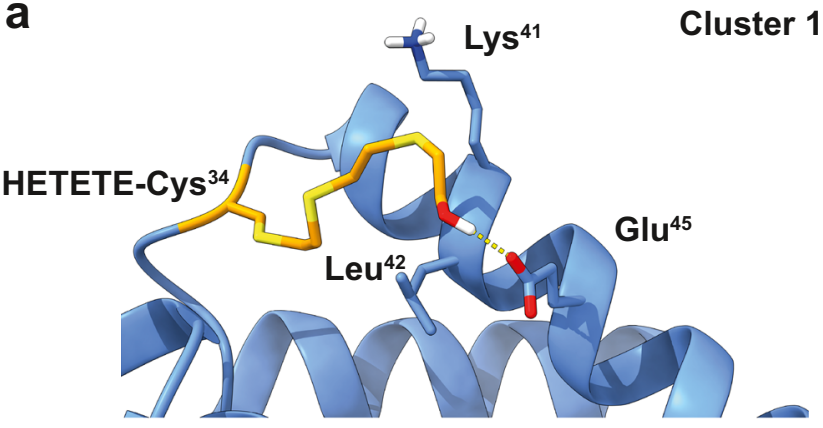

b

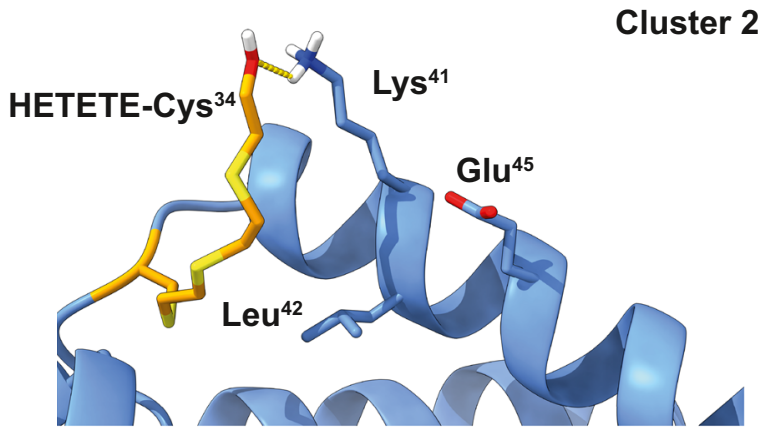

C

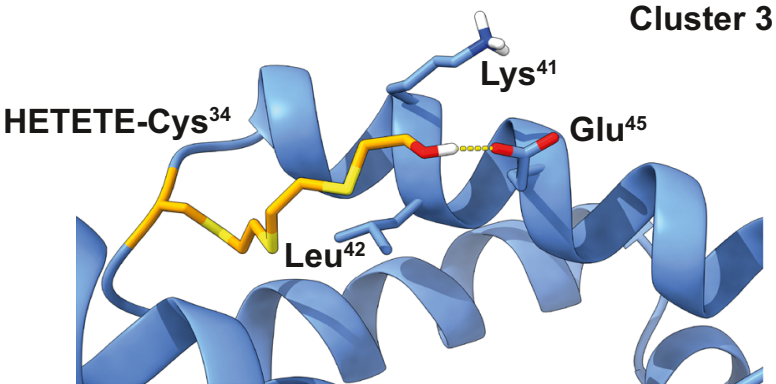

Fig. 5 Structural environment around HETETE-Cys ${ }^{34}$ in the three most populated clusters $(\mathbf{a}-\mathbf{c})$ after cluster analysis. Important hydrogen bonding partners ( $\mathrm{Lys}^{41}$ and $\mathrm{Glu}^{45}$ ) as well as important hydrophobic interaction partners $\left(\mathrm{Leu}^{42}\right.$ and $\left.\mathrm{Lys}^{41}\right)$ are highlighted 


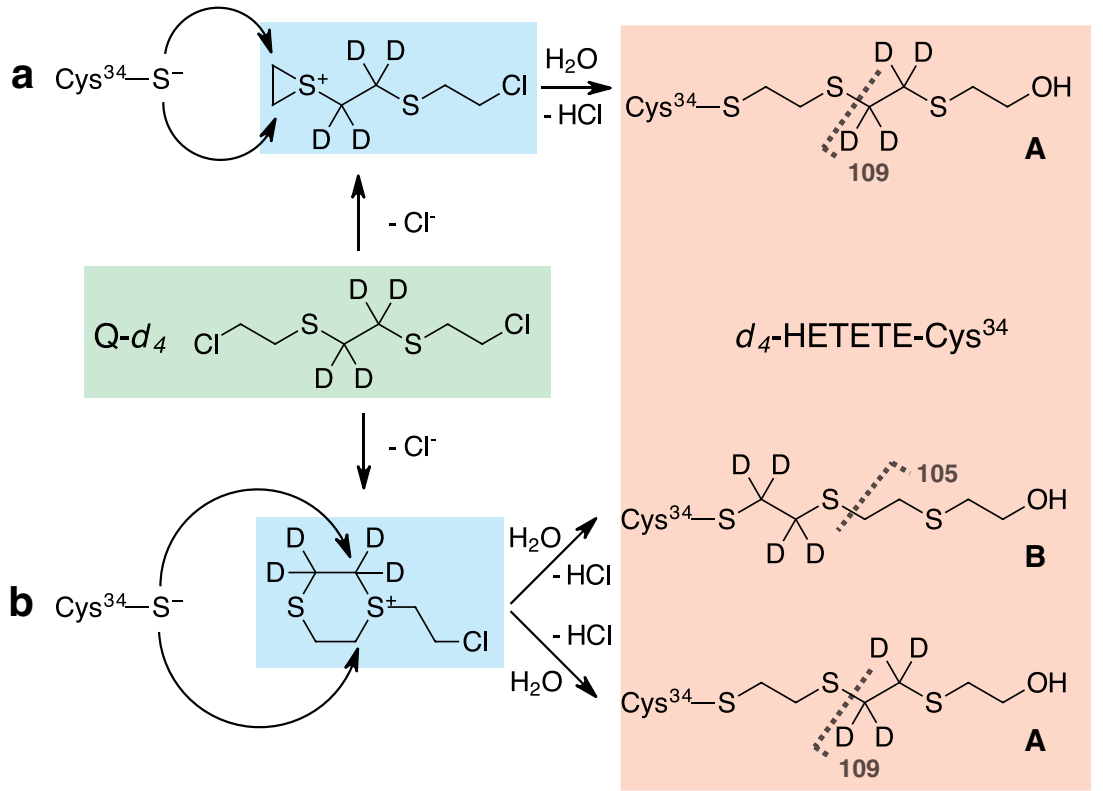

Fig. 6 Proposed reaction mechanism for the alkylation of $\mathrm{Cys}^{34}$ in HSA by Q. a Reaction of Q- $d_{4}$ (highlighted in green) with $\mathrm{Cys}^{34}$ via the episulfonium ion (highlighted in blue) and hydrolysis of the terminal chlorine atom yielding product A (highlighted in red) producing a deuterated product ion with a nominal mass of 109 in MS/MS

In conclusion, the $\mathrm{MD}$ simulations show that adduction of $\mathrm{Cys}^{34}$ by Q resulting in HETETE-Cys ${ }^{34}$ does not disturb the overall structural rigidity of subdomain IA of HSA, and that within certain steric constraints, the protein can accommodate the quite big HETETE moiety well. HETETE-protein interactions are dominated by hydrogen bonding to $\mathrm{Lys}^{41}$ and $\mathrm{Glu}^{45}$ and hydrophobic interactions with Lys ${ }^{41}$ and $\mathrm{Leu}^{42}$.

\section{The role of six-membered ring sulfonium ions as re- active species with HSA}

Three-membered ring episulfonium ions are the only reactive species formed by SM (Fig. 1d). In addition, Q is also able to form six-membered ring sulfonium ions (Fig. 1f). The latter have been observed in aqueous solution as reactive hydrolysis intermediates with significantly higher stability and lifetime than the episulfonium ions [21]. They are also present in significant amounts in old mustard munitions [17]. We were interested if these ions also play a role as reactive intermediates in the reaction of Q with Cys ${ }^{34}$ of HSA and made use of the partially deuterated variant of Q, 1,2-bis(2-chloroethylthio)$d_{4}$-ethane (Q- $d_{4}$, Fig. 1c), as a probe. If the reaction between Q- $d_{4}$ and $\mathrm{Cys}^{34}$ proceeds exclusively via the episulfonium ion, the deuterated ethylene moiety will remain between the two sulfur atoms of Q- $d_{4}$ resulting in product A (Fig. 6, product A). A reaction proceeding via the six-membered ring sulfonium ion on the other hand would yield two different products depending on which electrophilic carbon atom the nucleophilic fragmentation. b Reaction of Q- $d_{4}$ (green) with $\mathrm{Cys}^{34}$ via the sixmembered ring sulfonium ion (blue) and hydrolysis of the terminal chlorine atom yielding two different products - product A as described above and product B yielding the nondeuterated product ion at about $\mathrm{m} / \mathrm{z}$ 105 in MS/MS analysis

$\mathrm{S} \gamma$ of $\mathrm{Cys}^{34}$ reacts with (Fig. 6, products A and B). One reaction product is again product $\mathrm{A}$, while the second reaction product $\mathrm{B}$ contains the deuterated ethylene moiety in a position directly adjacent to the $\mathrm{S} \gamma$ of $\mathrm{Cys}^{34}$. Accordingly, mass spectrometric fragmentation by CID should result in a product ion with a nominal mass of 109 derived from product $A$ and in the product ion with a nominal mass of 105 derived from product B (Fig. 6). To elaborate the occurrence of these product ions, $d_{4}$-HETETE$\mathrm{CP}$ was subjected to MS/HR MS.

The observation of only very small amounts of the product ion at about $\mathrm{m} / \mathrm{z} .105$ compared with that at about $\mathrm{m} / \mathrm{z}, 109$ shows that six-membered sulfonium ions of Q or the half-hydrolyzed Q-chlorohydrin do not play an important role as reactive intermediates in the reaction of Q with $\mathrm{Cys}^{34}$ in HSA (data not shown). There are two likely explanations for this observation. Following the hydrolysis of $\mathrm{Q}$ in aqueous media by NMR spectroscopy, St. Quintin et al. were able to observe six-membered ring sulfonium ions as long-lived and therefore rather stable intermediates [21]. As high stability and long lifetimes are a result of reduced reactivity, we conclude that episulfonium ions are more reactive and therefore should react with $\mathrm{Cys}^{34}$ at higher reaction rates. The second explanation is that the protein environment around $\mathrm{Cys}^{34}$ imposes sterical hindrance for the nucleophilic attack of the $\mathrm{S} \gamma$ of $\mathrm{Cys}^{34}$ on the electrophilic carbon atoms of the bulkier six-membered ring sulfonium ion. 


\section{Potential forensic application}

While verification analysis of biomedical samples generally aims to prove or disprove exposure of a victim to a certain chemical agent, there is a growing interest in the possibility to conduct source attribution of a chemical agent. Source attribution means to trace the agent back to a specific synthesis method, reaction batch, specific precursor chemicals, or an existing stockpile. The chemical signatures of environmental samples have been the subject of academic interest [51-54] but have also been used in real cases [55]. So far, biomedical samples have not been considered for source attribution for several reasons: The intact chemical agent and the potential by-products and impurities are normally no longer present in vivo. Biotransformation processes alter compound compositions and impurities that might serve as signatures. In addition, such signatures are typically present in either extremely low concentration or they are biotransformed and excreted from the body seriously impeding their bioanalytical detection.

Sulfur mustards exhibit a complex synthesis and degradation chemistry with a significant number of impurities still being potent vesicants [56]. As described above, Q is an important impurity of SM and its relative amounts depend on the synthesis route, storage conditions, and age. The parallel detection of HETE, HETETE, and potential other adducts of HSA could provide valuable forensic information. In the absence of environmental samples, it might provide clues pointing to the type of mustard used. If a sample of the agent was available, the comparison might allow to conclude whether the exposure was caused by that specific batch of the agent. As adducts with endogenous proteins are regularly detected in the low ppb range, sufficient sensitivity of the method will be challenging, especially if the relative amounts of $\mathrm{Q}$ or other blistering impurities are low. Further investigations on human plasma samples of exposed individuals - including retrospective analysis of stored samples - are required for a detailed assessment.

Acknowledgments We thank the OPCW Laboratory (Rijswijk, The Netherlands) for making 1,2-bis(2-hydroxyethylthio) ethane and 1,2-bis(2-hydroxyethylthio)- $d_{4}$-ethane available for this work. We thank Marina Dentzel (InstPharmToxBw) for her excellent technical assistance.

Funding Open Access funding provided by Projekt DEAL.

\section{Compliance with ethical standards}

Conflict of interest The authors declare that they have no conflict of interest.

Human and animal rights and informed consent Research was carried out without human participants and animals.

Open Access This article is licensed under a Creative Commons Attribution 4.0 International License, which permits use, sharing, adaptation, distribution and reproduction in any medium or format, as long as you give appropriate credit to the original author(s) and the source, provide a link to the Creative Commons licence, and indicate if changes were made. The images or other third party material in this article are included in the article's Creative Commons licence, unless indicated otherwise in a credit line to the material. If material is not included in the article's Creative Commons licence and your intended use is not permitted by statutory regulation or exceeds the permitted use, you will need to obtain permission directly from the copyright holder. To view a copy of this licence, visit http://creativecommons.org/licenses/by/4.0/.

\section{References}

1. Kehe K, Szinicz L. Medical aspects of sulfur mustard poisoning. Toxicology. 2005;214:198-209.

2. Johnson NH, Larsen JC, Meek EC. Historical perspective of chemical warfare agents. In: Gupta R, editor. Handbook of toxicology of chemical warfare agents. 3rd ed. San Diego: Elsevier Inc./ Academic; 2020. p. 17-26.

3. Quillen C. The Islamic State's evolving chemical arsenal. Stud Confl Terror. 2016;39:1019-30.

4. John H, Balszuweit F, Steinritz D, Kehe K, Worek F, Thiermann H. Toxicokinetic aspects of nerve agents and vesicants. In: Gupta R, editor. Handbook of toxicology of chemical warfare agents. 3rd ed. San Diego: Elsevier Inc./Academic; 2020. p. 875-929.

5. Blum MM, Mamidanna MRVS. Analytical chemistry and the chemical weapons convention. Anal Bioanal Chem. 2014;406:5067-9.

6. Convention on the prohibition of the development, production, stockpiling and use of chemical weapons and on their destruction, current version 27 September 2005, https://www.opcw.org/sites/ default/files/documents/CWC/CWC_en.pdf

7. Gandor F, Gawlik M, Thiermann H, John H. Evidence of sulfur mustard exposure in human plasma by LC-ESI MS/MS detection of the albumin-derived alkylated HETE-CP dipeptide and chromatographic investigation of its cis/trans isomerism. J Anal Toxicol. 2015;39:270-9.

8. John H, Gandor F, Gawlik M, Thiermann H. LC-ESI MS/MS detection of the alkylated dipeptide HETE-CP to prove sulfur mustard exposure: application to plasma samples provided by the Organisation for the Prohibition of Chemical Weapons. Toxichem Krimtech. 2015;82:211-7.

9. Siegert M, Gandor F, Kranawetvogl A, Börner H, Thiermann H, John H. Methionine ${ }^{329}$ in human serum albumin: a novel target for alkylation by sulfur mustard. Drug Test Anal. 2019;11:659-68.

10. Noort D, Hulst A, de Jong L, Benschop H. Alkylation of human serum albumin by sulfur mustard in vitro and in vivo: mass spectrometric analysis of a cysteine adduct as a sensitive biomarker of exposure. Chem Res Toxicol. 1999;12:715-21.

11. Steinritz D, Striepling E, Rudolf KD, Schröder-Kraft C, Püschel K, Hullard-Pulstinger A, et al. Medical documentation, bioanalytical evidence of an accidental human exposure to sulfur mustard and general therapy recommendations. Toxicol Lett. 2016;244:112-20.

12. John H, Koller M, Worek F, Thiermann H, Siegert M. Forensic evidence of sulfur mustard exposure in real cases of human poisoning by detection of diverse albumin-derived protein-adducts. Arch Toxicol. 2019;93:1881-91.

13. John H, Siegert M, Gandor F, Gawlik M, Kranawetvogl A, Karaghioshoff K, et al. Optimized verification method for detection of an albumin-sulfur mustard adduct at $\mathrm{Cys}^{34}$ in plasma by $\mu \mathrm{LC}$-ESI MS/ MS using a hybrid quadrupole time-of-flight tandem mass spectrometer after direct plasma proteolysis. Toxicol Lett. 2016;244:103-11. 
14. John H, Willoh S, Hörmann P, Siegert M, Vondran A, Thiermann $\mathrm{H}$. Procedures for analysis of dried plasma using microsampling devices to detect sulfur mustard albumin adducts for verification of poisoning. Anal Chem. 2016;88:8787-94.

15. Gasson J, McCombie H, Williams AH, Woodward FN. New organic sulphur vesicants. Part IV. 1:2-Di-(2-chloro-ethylthio) ethane and its analogues. J Chem Soc. 1948:44-6.

16. Timperley CM, Black RM, Bird M, Holden I, Mundy JL, Read RW. Hydrolysis and oxidation products of the chemical warfare agents 1,2-bis[(2-chloroethyl)thio] ethane Q and 2,2'-bis(2chloroethylthio) diethyl ether T. Phosphorus Sulfur Silicon Relat Elem. 2003;178:2027-46.

17. National Research Council. Interim design assessment for the blue grass chemical agent destruction pilot plant. Washington, DC: The National Academies Press; 2005.

18. Bennett GM, Whincop EM. Some derivatives of monothioethylene glycol. J Chem Soc. 1921;119:1860-4.

19. Vocci FJ, Ballard TA, Yevich P, Punte CL. Inhalation toxicity studies with aerosols of sesqui-mustard. Toxicol Appl Pharmacol. 1963;5:677-84.

20. Sassenrath EN, Morrison DC, Larson AM, Greenberg DM. Evaluation of the carcinostatic activity of 1,2-bis(ß-chloroethylthio) ethane. Cancer Res. 1955;15:755-9.

21. St. Quintin TD, Leslie DR, Collins JG. Hydrolysis of sesquimustards. Aust J Chem. 2003;56:309-13.

22. D'Agostino PA, Provost PA. Capillary column isobutane chemical ionization mass spectrometry of mustard and related compounds. Biomed Environ Mass Spectrom. 1988;15:553-64.

23. D'Agostino PA, Provost PA. Capillary column gas chromatography-ammonia and deuterated ammonia chemical ionization mass spectrometry of sulfur vesicants. J Chromatogr A. 1992;600:267-72.

24. D'Agostino PA, Provost PA. Capillary column electron impact and ammonia chemical ionization gas chromatographic-mass spectrometric and gas chromatographic-tandem mass spectrometric analysis of mustard hydrolysis products. J Chromatogr A. 1993;645:283-92.

25. D'Agostino PA, Provost PA, Hancock JR. Analysis of mustard hydrolysis products by packed capillary liquid chromatography-electrospray mass spectrometry. J Chromatogr A. 1998;808:177-84.

26. Lemire SW, Ash DH, Johnson RC, Barr JR. Mass spectral behavior of the hydrolysis products of sesqui- and oxy-mustard type chemical warfare agents in atmospheric pressure chemical ionization. $\mathrm{J}$ Am Soc Mass Spectrom. 2007;18:1364-74.

27. Ash DH, Lemire SW, McGrath SC, McWilliams LG, Barr JR. Multianalyte quantification of five sesqui- and ethyl ether oxymustard metabolites in human urine by liquid chromatographyatmospheric pressure chemical ionization-tandem mass spectrometry. J Anal Toxicol. 2008;32:44-50.

28. Kaushik MP, Rana H. Facile one-step synthesis of dithiaalkanediols. Org Prep Proced Int. 2005;37:267-72.

29. Abraham MJ, Murtola T, Schulz R, Páll S, Smith JC, Hess B, et al. GROMACS: high performance molecular simulations through multi-level parallelism from laptops to supercomputers. SoftwareX. 2015;1-2:19-25.

30. Schmid N, Eichenberger AP, Choutko A, Riniker S, Winger M, Mark AE, et al. Definition and testing of the GROMOS forcefield versions 54A7 and 54B7. Eur Biophys J. 2011;40:843-56.

31. Stroet M, Caron B, Visscher KM, Geerke DP, Malde AK, Mark AE. Automated topology builder version 3.0: prediction of solvation free enthalpies in water and hexane. J Chem Theory Comput. 2018;14:5834-45.

32. Pettersen EF, Goddard TD, Huang CC, Couch GS, Greenblatt DM, Meng EC, et al. UCSF Chimera-a visualization system for exploratory research and analysis. J Comput Chem. 2004;25:1605-12.

33. Berendsen HJC, Postma JPM, van Gunsteren WF, Hermans J. Interaction models for water in relation to protein hydration. In:
Pullman B, editor. Intermolecular forces. Dordrecht: Reidel; 1981. p. 331-42.

34. Hess B. P-LINCS: a parallel linear constraint solver for molecular simulation. J Chem Theory Comput. 2008;4:116-22.

35. Pall S, Hess B. A flexible algorithm for calculating pair interactions on SIMD architectures. Comput Phys Commun. 2013;184:2641-50.

36. Darden T, York D, Pedersen L. Particle mesh Ewald: an $N \cdot \log (\mathrm{N})$ method for Ewald sums in large systems. J Chem Phys. 1993;98: 10089-92

37. Essmann U, Perera L, Berkowitz ML, Darden T, Lee H, Pedersen LGA. A smooth particle mesh Ewald method. J Chem Phys. 1995; 103:8577-93.

38. Bussi G, Donadio D, Perinello M. Canonical sampling through velocity rescaling. J Chem Phys. 2007;126:014101.

39. Parrinello M, Rahman A. Polymorphic transitions in single crystals: a new molecular dynamics method. J Appl Phys. 1981;52:7182-90.

40. Nosé S, Klein ML. Constant pressure molecular dynamics for molecular systems. Mol Phys. 1983;50:1055-76.

41. Work instruction for the reporting of the results of the OPCW biomedical proficiency tests. QDOC/LAB/WI/BioPT04. The Hague: The Organisation for the Prohibition of Chemical Weapons (OPCW); 2020

42. Fasano M, Curry S, Terreno E, Galliano M, Fanali G, Narciso P, et al. The extraordinary ligand binding properties of human serum albumin. IUBMD Life. 2005;57:787-96.

43. Lambrinidis G, Vallianatou T, Tsantili-Kakoulidou A. In vitro, in silico and integrated strategies for the estimation of plasma protein binding. A review. Adv Drug Deliv Rev. 2015;86:27-45.

44. Paris G, Ramseyer C, Enescu M. A principal component analysis of the dynamics of subdomains and binding sites in human serum albumin. Biopolymers. 2014;101:561-72.

45. Fabisiak JP, Sedlov A, Kagan VE. Quantification of oxidative/ nitrosative modification of Cys34 in human serum albumin using a fluorescence-based SDS-PAGE assay. Antioxid Redox Signal. 2002;4:855-65.

46. Castellanos MM, Colina CM. Molecular dynamics simulations of human serum albumin and role of disulfide bonds. Phys Chem B. 2013;117:11895-905.

47. Bonanata J, Turell L, Antmann L, Ferrer-Sueta G, Botasini S, Méndez E, et al. The thiol of human serum albumin: acidity, microenvironment and mechanistic insights on its oxidation to sulfenic acid. Free Radic Biol Med. 2017;108:952-62.

48. He XM, Carter DC. Atomic structure and chemistry of human serum albumin. Nature. 1992;358:209-15.

49. Daura X, Gademann K, Jaun B, Seebach D, van Gunsteren WF, Mark AE. Peptide folding: when simulation meets experiment. Angew Chem Int Ed. 1999;38:236-40.

50. Dyson HJ, Wright PE, Scheraga HA. The role of hydrophobic interactions in initiation and propagation of protein folding. Proc Natl Acad Sci U S A. 2006;103:13057-61.

51. Ovenden SPB, Webster RL, Micich E, McDowall LJ, McGill NW, Williams $\mathrm{J}$, et al. The identification of chemical attribution signatures of stored VX nerve agents using NMR, GC-MS, and LCHRMS. Talanta. 2020;211:120753.

52. Fraga CG, Pérez Acosta GA, Crenshaw MD, Wallace K, Mong GM, Colburn HA. Impurity profiling to match a nerve agent to its precursor source for chemical forensics applications. Anal Chem. 2011;83:9564-72.

53. Holmgren KH, Valdez CA, Magnusson R, Vu AK, Lindberg S, Williams AM, et al. Part 1: tracing Russian VX to its synthetic routes by multivariate statistics of chemical attribution signatures. Talanta. 2018;186:586-96.

54. Fraga CG, Bronk K, Dockendorff BP, Heredia-Langner A. Organic chemical attribution signatures for the sourcing of a mustard agent and its starting materials. Anal Chem. 2016;88:5406-13. 
55. United Nations Security Council. Document S/2017/904, seventh report of the Organisation for the Prohibition of Chemical Weapons-United Nations joint investigative mechanism. 2017. https://undocs.org/S/2017/904. Accessed 5 June 2020.

56. Rosenblatt DH, Small MJ, Kimmell TA, Anderson AW. Background chemistry for chemical warfare agents and decontamination processes in support of delisting waste streams at the U.S. Army Dugway Proving Ground, Utah. ANL/EAD/TM-56. Argonne National Laboratory; 1996.

Publisher's note Springer Nature remains neutral with regard to jurisdictional claims in published maps and institutional affiliations.

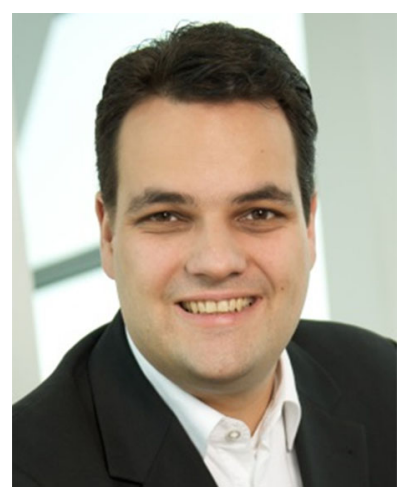

Marc-Michael Blum is an independent consultant for analytical and laboratory solutions in CBRN defense and previously worked as the head of the Laboratory of the Organisation for the Prohibition of Chemical Weapons (OPCW), Rijswijk, The Netherlands. He studied chemistry at the Technical University of Braunschweig, Germany, and obtained his Ph.D. in biochemistry from the University of Frankfurt, Germany. He also holds an M.A. in War Studies from King's College, London, UK. His research interests include analytical methods for the detection of chemical threat agents, chemical signatures for potential source attribution, biomarkers for proof of exposure, and molecular foundations of toxic action.

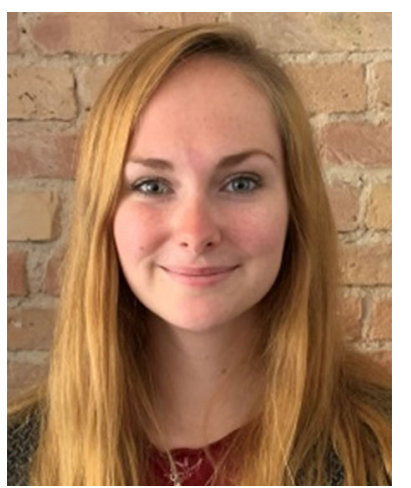

Annika Richter studied chemistry at the Humboldt-Universität zu Berlin, Germany, and is currently finishing her master's thesis at the Bundeswehr Institute of Pharmacology and Toxicology in the working group of Prof. Dr. John with a focus on albumin adducts of sulfur mustards. Soon she will start her Ph.D. studies at the Leibnitz Institute for Molecular Pharmacology in Berlin Buch.

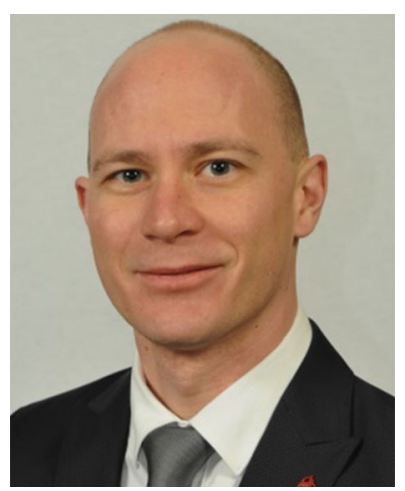

Markus Siegert studied chemistry at the Ludwig-MaximiliansUniversity, Munich, Germany, and finished his master's thesis in 2015 in collaboration with the Bundeswehr Institute of Pharmacology and Toxicology in the working group of Prof. Dr. John. Currently, he is finishing his Ph.D. studies in the same laboratory as a student of the Humboldt-Universität zu Berlin, Germany. Both his master's thesis and doctorate focus on novel bioanalytical methods for the detection of protein adducts with the chemical warfare agent sulfur mustard.

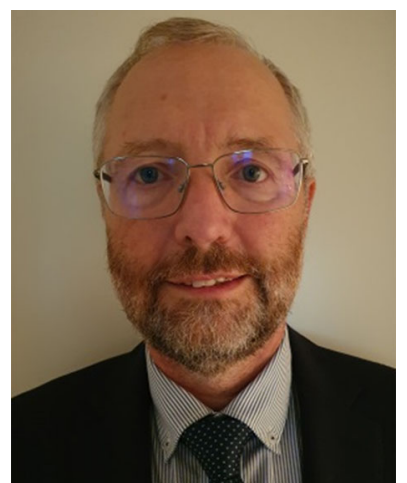

Horst Thiermann studied medicine at the University of Regensburg, Germany, and the Technical University of Munich, Germany. He is the director, colonel (MC), of the Bundeswehr Institute of Pharmacology and Toxicology, Munich, Germany, and Adjunct Professor at the Technical University of Munich. He specializes in pharmacology and toxicology as well as in clinical pharmacology. His main subject is research in medical defense against chemical weapons. He is

President of the European Association of Poisons Centres and Clinical Toxicologists (EAPCCT) and Vice-Chairman of the German Federal Institute for Risk Assessment's (BfR) Committee for the Assessment of Intoxications.

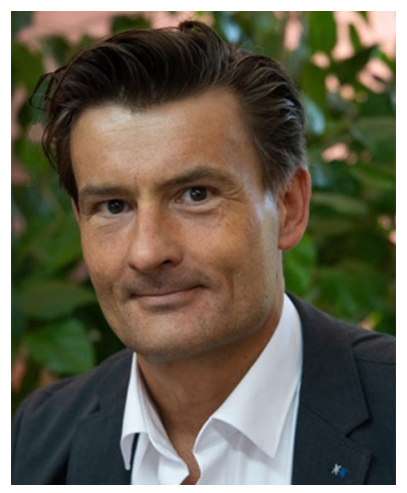

Harald John is Head of laboratory at the Bundeswehr Institute of Pharmacology and Toxicology, Munich, Germany. He studied chemistry and finished his Ph.D. thesis in analytical chemistry in Münster, Germany. He also studied toxicology at the Faculty of Medicine at the University of Leipzig, Germany, and completed his degree as a scientific specialist for toxicology. In 2016, he was appointed as Adjunct Professor for analytical chemistry at the Humboldt-Universität zu Berlin, Germany. His work in Munich is focused on the development of forensic mass spectrometry-based methods for post-exposure analysis of biological samples to verify poisoning with chemical warfare agents and related toxicants with a special focus on protein adducts. 